\title{
CSF Electrophoresis: An Adaptation Using Cellulose Acetate for the Identification of Oligoclonal Banding
}

\author{
D. W. PATY, M. DONNELLY AND M. E. BERNARDO
}

\begin{abstract}
SUMMARY: An adaptation of cellulose acetate electrophoresis for studying concentrated cerebrospinal fluid is described. Two hundred and twenty-one patients have been studied, and the specificity for multiple sclerosis and sub-acute sclerosing panencephalitis is discussed. This has been positive for oligoclonal banding $(O B)$ in $79 \%$ of patients with clinically definite multiple sclerosis.
\end{abstract}

RÉSUMÉ: Nous décrivons une nouvelle méthode d'étude du liquide céphalorachidien dérivée d'une adaptation de l'électrophorèse sur acétate de cellulose. Nous avons étudié 221 patients et discutons la spécificité des résultats dans la sclérose-enplaques et la panencéphalite sclérosante sub-aigue. Les résultats montrent une bande oligoclonale chez $79 \%$ des patients souffrant d'une sclérose-en-plaques cliniquement définie.
From the: Departments of Clinical Neurological Sciences, Instructional Resources and Clinical Biochemistry, University Hospital, University of Western Ontario, London, Ontario.

This work was presented in part at the 12th Canadian Congress of Neurological Sciences, Quebec City, June 17, 1977.

Reprint requests to: Dr. D. W. Paty, Department of Clinical Neurological Sciences, University Hospital, P.O. Box 5339, Postal Station A., London, Ontario N6A 5A5, Canada.
A number of studies in the literature in the last 10 years have shown that the cerebrospinal fluid (CSF) proteins in multiple sclerosis (MS) have a characteristic qualitative change in the gamma globulin region (Link \& Muller, 1971). This characteristic change has been referred to as the oligoclonal banding (OB) pattern of the CSF proteins. Most studies of this phenomenon have used agar gel or agarose preparations. We have adapted cellulose acetate electrophoresis with photographic enhancement for increasing contrast. The use of cellulose acetate rather than agar gel will make this procedure available to any clinical biochemistry laboratory that is now doing serum electrophoresis using cellulose acetate strips. Since this procedure has an $80 \%$ to $95 \%$ diagnostic accuracy for multiple sclerosis, it will be an important procedure to have in any general hospital laboratory.

\section{MATERIALS AND METHOD:} Patients:

Two hundred-twenty-one patients were studied. These patients came from the wards of the University Hospital, London, Ontario. Patients with clinically definite multiple sclerosis were identified according to Schumacher criteria (Schumacher, et al., 1965).

\section{Methods; Laboratory:}

CSF samples were centrifuged to remove debris. Proteins were concentrated $\mathrm{x} 100$ by use of a minicon B 15 concentrator (Amicon, Lexington, Mass.). Cellulose acetate electrophoresis was performed using a trisbarbital-sodium barbital buffer at $\mathrm{PH}$ 8.8 for 40 minutes at 200 volts. The strips were stained with ponceau $S$, de- stained, cleared, and dried. The dried strips were placed on chalk paper under matte glass and photographed at multiple exposure times using Kodak high speed film \#2575. This photographic enhancement brought out contrasts in the staining (fig.). The identification of $\mathrm{OB}$ was dependent upon visual inspection of the image on the photographic transparency using transmitted light. The presence of more than 2 transverse bands in the gamma globulin region was identified as oligoclonal banding (OB).

\section{RESULTS:}

The figure is a print made from several of the electrophoresis strips. The quality of the transparencies is much greater than that of the print. The bottom strip, of the 5 shown, is the normal distribution of CSF proteins. Each of the other 4 are from MS patients. The top strip has such a high concentration of protein in the gamma range that the single bands are obscured.

The table gives the results in the 221 patients studied. Ninety-five of these patients did not have MS. Of these 95 there was 1 band present in 20 , and a suspicion of 2 bands in 2 patients. The diagnoses in these 2 patients were arachnoiditis and myelopathy of unknown cause. This gives a doubtful positive in $2 \%$ of non multiple sclerosis patients. Two patients with SSPE were studied and a marked positive $O B$ was seen in both patients.

Sixty-two patients who satisfied accepted criteria for clinically definite MS were examined. Seven of these studies were technically unsatisfactory due to insufficient cerebrospinal fluid for concentration $\times 100$. Of the 55 adequate electrophoresis studies, 49 were 


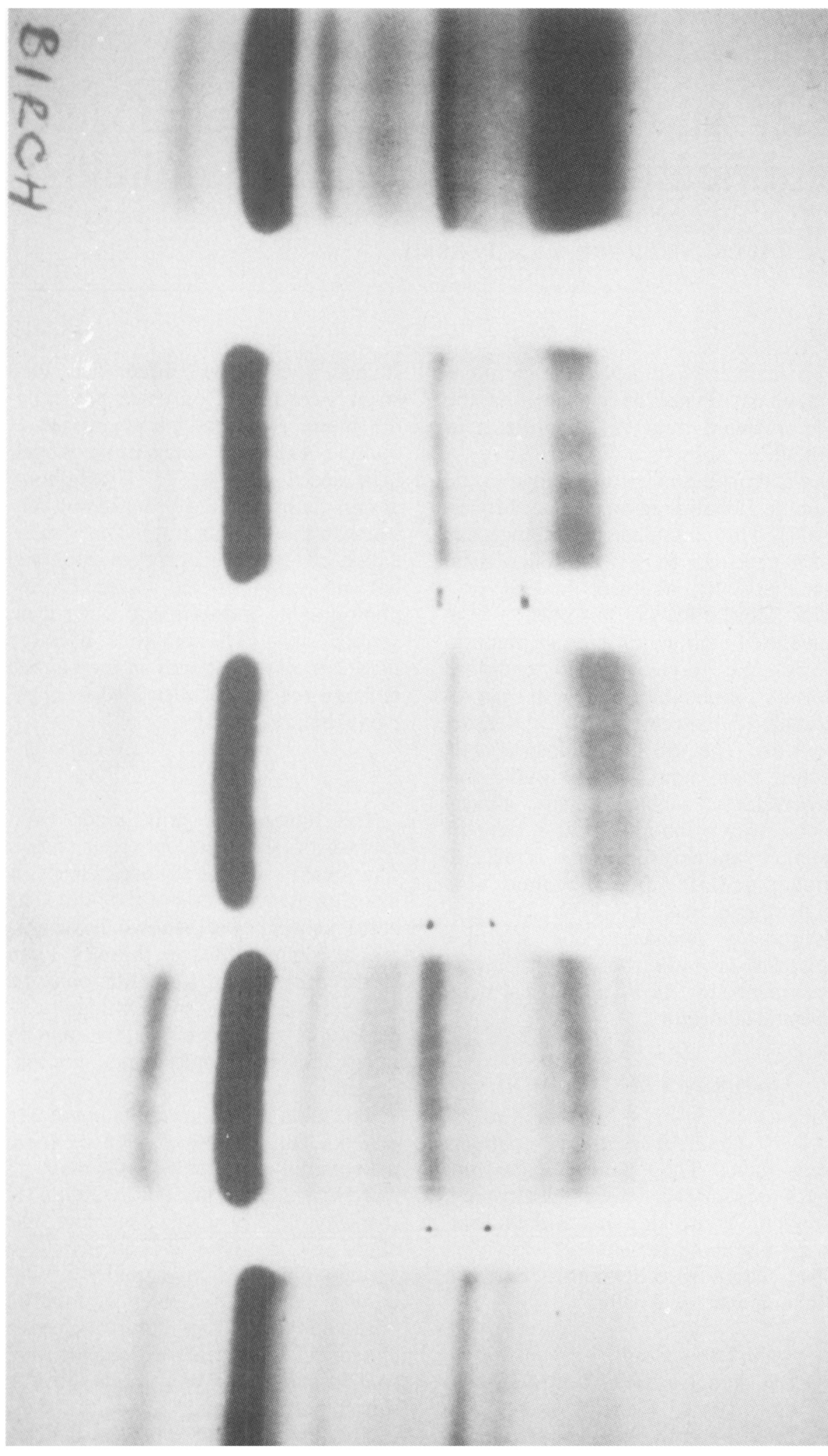

Cellulose acetate electrophoresis of 5 CSF The top strip has a very high protein consamples concentrated $\times 100$. The bottom centration in the gamma region that obstrip is a normal pattern. Each of the others sures the $O B$ pattern on this print but not has 2 or more transverse bands in the gam- on the original transparency. The gamma ma region and comes from an MS patient. region is to the right, albumin to the left. positive for OB. This gives an $89 \%$ positive rate in technically satisfactory studies. There is a $79 \%$ overall positive rate for all MS patients studied.

One hundred-eleven (111) patients with suspected MS have been studied. Forty-two (42) of these were positive for $\mathrm{OB}(38 \%)$.

\section{DISCUSSION:}

The diagnosis of multiple sclerosis is generally a clinical one. Most investigators would recognize the Schumacher critera (Schumacher, et al., 1965), for making a diagnosis of clinically definite MS. For many years it has been known that there is an increased percentage of gamma globulin in the cerebrospinal fluid protein in patients with MS (Kabat, Landow \& Moore, 1942). The incidence of this quantitative abnormality is thought to be about $70 \%$. The electrophoretic study of cerebrospinal fluid proteins has now shown that somewhere between 80 and $95 \%$ of Multiple Sclerosis patients probably have a qualitative change in the CSF proteins, and this is now referred to as oligoclonal banding (OB).

Most studies of cerebrospinal fluid for $O B$ have utilized agar or agarose as the medium for the electrophoresis. Since most hospital laboratories have the ability to perform serum electrophoresis using cellulose acetate strips, we thought we would try to adapt cellulose acetate for the study of CSF proteins as well. This procedure has proved to be relatively simple, and reliable. Visual inspection of the photographic transparency clearly shows an oligoclonal banding (OB) pattern in a majority of patients with clinically definite MS. This should now become a routine study for the investigation of patients with suspected MS. This combination of relatively simple electrophoresis techniques with photographic enhancement of image could make the search for oligoclonal banding in the CSF more widely available.

CSF changes of $\mathrm{OB}$ are not yet an accepted criteria for making a clinical diagnosis of MS. Clinical criteria of typical history with dissemination of lesions in time and space will remain the mainstay of the diagnosis. With greater availability, CSF electrophoresis should provide substantiating support 
TABLE 1

CSF ELECTROPHORESIS IN 221 PATIENTS

$\begin{array}{lccccc}\begin{array}{l}\text { Patient } \\ \text { Category }\end{array} & \mathrm{N} & \begin{array}{c}\text { \#Pos } \\ \text { for OB* }\end{array} & \begin{array}{c}\text { \% Pos } \\ \text { for OB }\end{array} & \begin{array}{c}\text { One Band } \\ \text { Seen }\end{array} & \begin{array}{c}\% \text { With } \\ \text { One Band }\end{array} \\ \text { MS total } & 62 & 49 & 79 \% & 6 & 10 \% \\ \text { TS } & 55 & 49 & 89 \% & 6 & 11 \% \\ \text { Suspected MS } & 111 & 42 & 38 \% & 13 & 18 \% \\ \text { Non MS } & 95 & ? 2 & 2 \% & 20 & 21 \% \\ \text { SSPE+ } & 2 & 2 & 100 \% & - & - \\ \text { * OB = Oligoclonal Banding. } & & & & \\ \text { ** TS = Technically Satisfactory. } & & & & \\ \text { + SSPE = Subacute Sclerosing Panencephalitis. } & & \end{array}$

in making a diagnosis in doubtful cases. The finding of $O B$ in an adult with chronic spinal cord dysfunction, double vision, loss of vision, or incoordination of limb and gait should provide strong support for a diagnosis of MS. Early accurate diagnosis is going to become increasingly important in substantuating clinical investigation, establishing prognosis, and for institution of appropriate therapy when it becomes available.

\section{REFERENCES}

KABAT, E., LANDOW, H., and MOORE, D. (1942). Electrophoretic patterns of concentrated cerebrospinal fluid. Pro Soc Exp Biol Med. 49: 260-263.

LINK, H., and MULLER, R. (1971). Immunoglobulins in multiple sclerosis and infections of the nervous system. Arch Neurol. 25: 326-344.

SCHUMACHER, G., BEEBE, G., KIBLER, R., KURLAND, L., KURTZKE, J,, MCDOWELL, F., NAGLER, B., SIBLEY, W. TOURTELLOTTE, W., WILLMON, T. (1965). Problems of experimental trials of therapy in multiple sclerosis: report by the panel on the evaluation of experimental trials of therapy in multiple sclerosis. Annals of N.Y. Academy of Sciences. 122: 552-568. 